\title{
Behavioral Inhibition as a Risk Factor for the Development of Childhood Anxiety Disorders: A Longitudinal Study
}

\author{
Peter Muris • Anna M. L. van Brakel • \\ Arnoud Arntz $\cdot$ Erik Schouten
}

Published online: 17 March 2010

(C) The Author(s) 2010. This article is published with open access at Springerlink.com

\begin{abstract}
This longitudinal study examined the additive and interactive effects of behavioral inhibition and a wide range of other vulnerability factors in the development of anxiety problems in youths. A sample of 261 children, aged 5 to 8 years, 124 behaviorally inhibited and 137 control children, were followed during a 3-year period. Assessments took place on three occasions to measure children's level of behavioral inhibition, anxiety disorder symptoms, other psychopathological symptoms, and a number of other vulnerability factors such as insecure attachment, negative parenting styles, adverse life events, and parental anxiety. Results obtained with Structural Equation Modeling indicated that behavioral inhibition primarily acted as a specific risk factor for the development of social anxiety symptoms. Furthermore, the longitudinal model showed additive as well as interactive effects for various vulnerability factors on the development of anxiety symptoms. That is, main effects of anxious rearing and parental trait anxiety were found, whereas behavioral inhibition and attachment had an interactive effect on anxiety symptomatology. Moreover, behavioral inhibition itself was also influenced by some of the vulnerability factors. These results provide support for dynamic, multifactorial models for the etiology of child anxiety problems.
\end{abstract}

\footnotetext{
P. Muris $(\square)$

Institute of Psychology, Erasmus University Rotterdam, Burgemeester Oudlaan 50, Suite T13-37, P.O. Box 1738, Rotterdam, The Netherlands

e-mail: muris@fsw.eur.nl
}

A. M. L. van Brakel · A. Arntz · E. Schouten Department of Clinical Psychological Science, Mastricht University, Maastricht, The Netherlands
Keywords Behavioral inhibition - Anxiety disorders symptoms · Social phobia $\cdot$ Multifactorial model · Children · Longitudinal study

\section{Introduction}

Behavioral inhibition is a temperamental trait characterized by a relatively consistent pattern of behavioral and emotional responses to unfamiliar people and novel stimuli and situations. That is, inhibited children typically respond with restraint, caution, and withdrawal to novel objects and situations, and they are usually timid, fearful, and shy with unfamiliar people (Kagan et al. 1988; Kagan 1994). Behavioral inhibition shows moderate to good levels of continuity during childhood and is to a certain extent also associated with aspects of adult personality (for a review of the research on lifetime continuity in behavioral inhibition, see Fox et al. 2005). During the past 20 years, a number of studies have shown that there is an increased prevalence of anxiety disorders among behaviorally inhibited children (see for reviews Hirshfeld-Becker et al. 2004, 2008a). Noteworthy in this regard is the 3-year longitudinal study by Biederman et al. (1993) who found that children initially identified as behaviorally inhibited were subsequently more likely to develop anxiety disorders as compared to control children (i.e., children who at study onset were not classified as behaviorally inhibited). It should be noted that in particular children with stable behavioral inhibition ran an increased risk for developing pathological anxiety (see also Hirshfeld-Becker et al. 1992).

While there is clear evidence indicating that behavioral inhibition is an important risk factor for the development of pathological anxiety in youths, it should also be noted that not every child with an inhibited temperament develops an 
anxiety disorder (see for instance Biederman et al. 1990), and so the question arises under what conditions behaviorally inhibited children develop anxiety disorders. Further, not every anxious child has a behaviorally inhibited temperament (Turner et al. 1996). As with other types of psychopathology, it is generally assumed that anxiety disorders are the result of multiple variables and influences (Muris 2007; Vasey and Dadds 2001). Therefore, when studying the role of behavioral inhibition in childhood anxiety disorders, one should also consider other vulnerability factors so that it becomes possible to study the unique and interactive effects of this temperamental trait. In the literature, a number of other factors have been identified that may play a role in the formation of anxiety problems, which may operate in conjunction or interaction with behavioral inhibition. These include an insecure parentchild attachment, negative parenting styles, parental anxiety, and adverse life events (see also Rapee et al. 2009), and will be discussed in the following paragraphs.

In their longitudinal study, Warren et al. (1997) found a specific link between insecure (in particular, ambivalent) attachment measured in infancy and anxiety disorders that were assessed some 16 years later. A couple of studies have examined insecure attachment in interaction with behavioral inhibition (e.g., Calkins and Fox 1992; Mannasis et al. 1995; Muris and Meesters 2002; Shamir-Essakow et al. 2005). Altogether, the results of these studies have shown that children who combine a behaviorally inhibited temperament with an insecure attachment status display the highest levels of anxiety disorders symptoms, which of course indicates that these two vulnerability factors have a cumulative effect on the development of anxiety pathology in youths.

Two parenting dimensions that have been consistently associated with the development of anxiety in children and adolescents are overprotection and anxious rearing (e.g., Wood et al. 2003). Overprotection can best be described as parental behaviors aimed at guiding children during their daily activities. These parental behaviors often have the effect of directing the child and reducing the development of autonomy (Rapee 1997). Anxious rearing pertains to the explicit encouragement of anxious cognitions and avoidance behaviors in children (e.g., Barrett et al. 1996; Grüner et al. 1999). Several studies have yielded evidence for the proposed relationship between overprotective and anxious rearing behaviors and anxiety disorder symptoms, some of them relying on direct observation of parent-child interactions (Hudson and Rapee 2001; Whaley et al. 1999) and others making use of questionnaires that intend to measure children's perceptions of parental rearing behaviors (Grüner et al. 1999; Muris et al. 2000, 2003). Overprotective and anxious parenting have been found to play a unique role in the development of childhood anxiety symptoms when examined together with behavioral inhibition (Van Brakel et al. 2006), and there are also studies indicating that parenting interacts with an inhibited temperament (Rubin et al. 1997, 1999).

Clear associations exist between adverse life events and psychiatric disorders in children and adolescents and these also include anxiety disorders (Tiet et al. 2001). It seems plausible to assume that behaviorally inhibited children are particularly prone to develop anxiety problems when confronted with negative life events. Brozina and Abela (2006) tested this idea and examined the relationship between behavioral inhibition and anxiety symptoms within a diathesis-stress framework. The results of this study indicated that only behaviorally inhibited children who experienced high levels of stressful events (e.g., fighting parents, being teased at school, being punished) displayed an increase of anxiety symptoms during a 6-weeks period. In contrast, behaviorally inhibited children who did not experience such events exhibited a decrease in anxiety symptoms.

Research has shown that children of parents with anxiety disorders run a greater risk for developing anxiety disorders themselves (Biederman et al. 1991). Furthermore, Rosenbaum et al. (1988) reported that a substantial proportion of the children of parents with clinically significant anxiety disorders were behaviorally inhibited. Finally and most importantly, there is also evidence to demonstrate that children with a behaviorally inhibited temperament who also have parents suffering from an anxiety disorder are most vulnerable to develop anxiety disorders (e.g., Rosenbaum et al. 1992).

Many studies suggest that behavioral inhibition is associated with a wide range of anxiety-related symptoms and disorders (Biederman et al. 1993; Broeren and Muris 2010; Gest 1997; Muris et al. 1999, 2001, 2003, 2009; Reznick et al. 1992; Shamir-Essakow et al. 2005), but there are also several studies that indicate that behavioral inhibition is a more specific risk factor and is only involved in the pathogenesis of social anxiety. For example, TownsleyStemberger et al. (1995) noted that social phobic patients reported significantly higher levels of shyness (which seems to be a clear marker of behavioral inhibition) in childhood than did control participants. In line with these findings, Mick and Telch (1998) asked students with high symptom levels of social anxiety or generalized anxiety to retrospectively report their level of behavioral inhibition during childhood. These researchers found that behavioral inhibition in childhood was strongly associated with symptoms of social anxiety in adulthood, but not with symptoms of generalized anxiety. Hayward et al. (1998) showed that adolescents $(N=2242)$ who retrospectively reported that they had been behaviorally inhibited in childhood were four to five times more likely to suffer from 
a social phobia than adolescents who reported that they had not been behaviorally inhibited in childhood. Recently, Gladstone et al. (2005) have also demonstrated that a behaviorally inhibited temperament in childhood may be a specific vulnerability factor to social anxiety rather than to anxiety in general.

Adolescents' self-reports of behavioral inhibition are not only positively correlated with anxiety, but also with depression symptoms (Muris et al. 1999, 2001, 2003). One explanation for this association is that behavioral inhibition acts as a common vulnerability factor to both anxiety and depression. Another explanation could be that the association between behavioral inhibition and depression is a statistical artifact of the strong associations between anxiety and both behavioral inhibition and depression (Brozina and Abela 2006). Gladstone and Parker (2006) obtained evidence to suggest that the presence of a behaviorally inhibited temperament may pose a developmental risk for lifetime depression. However, it is important to note that the relationship between behavioral inhibition and depression was dependent on the presence of social anxiety. That is, only behaviorally inhibited children who had developed social anxiety were prone to develop a depression (see also Muris et al. 2003). Nevertheless, other studies can be found in the literature indicating that behavioral inhibition is clearly associated with depression (Hirshfeld-Becker et al. 2003; Gullone et al. 2006; Jaffee et al. 2002; Shatz 2005). Taken together, although it has been proposed that behavioral inhibition is associated with the development of a wide range of anxiety-related symptoms and disorders, there is also evidence indicating that this temperamental trait acts as a more specific risk factor for social anxiety (see also Chronis-Tuscano et al. 2009; Essex et al. 2010; Hirshfeld-Becker et al. 2007). In addition, more research is required to examine whether behavioral inhibition is specifically linked to anxiety symptomatology or whether this temperamental trait also plays a role in the etiology of depression or even other psychological disorders in youths.

So far, research has demonstrated that behavioral inhibition, and other vulnerability factors like insecure attachment, negative parenting styles, adverse life events, and parental anxiety contribute to the development of anxiety disorders in youths. Only a few studies can be found that have investigated whether combinations of these factors yield an increased risk for anxiety problems (e.g., Calkins and Fox 1992; Van Brakel et al. 2006; Brozina and Abela 2006), but no study can be found that examined the additive and interactive effects of behavioral inhibition and a wide range of other vulnerability factors in the development of pathological anxiety in youths (HirshfeldBecker et al. 2008b). With this issue in mind, the present longitudinal research project was set-up. A group of 261 5- to 8-year-old children, 124 who displayed high levels of behavioral inhibition and 137 control children, were followed during a 3-year period. Each year, an assessment took place to measure children's level of behavioral inhibition, anxiety disorder symptoms, other psychopathological symptoms, and a number of other vulnerability factors such as insecure attachment, negative parenting, adverse life events, and parental anxiety. In this way, it became possible to study (1) the unique and interactive effect of behavioral inhibition on the development of anxiety symptoms, and (2) whether behavioral inhibition plays a role in the development of anxiety problems in general, social anxiety, or a broad range of psychopathological symptoms (e.g., depression).

It was hypothesized that behavioral inhibition would be predictive of anxiety symptoms, especially social anxiety symptoms, over the 3-year period. Consistent with a diathesis-stress framework (see Brozina and Abela 2006), it was expected that behaviorally inhibited children who experienced high levels of stress as a result of adverse life events would be particularly prone to display an increase of anxious symptoms. Further, insecure attachment, an anxious and overprotective parenting style, and parental anxiety were all expected to play a unique role in the development of children's anxious symptoms, and it was explored to what extent these vulnerability factors interacted with behavioral inhibition.

\section{Method}

Participants and Procedure

The parents of 2,547 children of 40 normal primary schools in the southern part of The Netherlands were approached by mail. By means of a letter, parents received information about this longitudinal research project, and they were asked to give their consent about their child's participation in the study. In addition, parents were invited to complete the Behavioral Inhibiton Instrument (BII; see below) and to return materials to the researchers in a sealed envelop. One-thousand-and-one-hundred-seventy-six parents (46.2\%) responded positively to this invitation and allowed their child to participate in the study. Two-hundred-and-twentyseven of these children were identified as behaviorally inhibited by means of the BII scores as provided by their parents, and 184 control children were selected because they scored in the normal range of the BII. The parents of these 411 children were approached by phone to explain the procedure of the longitudinal study once again. After this phone call, 261 parent couples were convinced about their commitment to the study for a couple of years, which resulted in a final sample of 124 behaviorally inhibited children and 137 control children. Both groups were 
Table 1 Assessment occasions of this longitudinal project as well as the specific instruments that were administered on each point-in-time

\begin{tabular}{llll}
\hline Screening & Occasion I 6 months later & Occasion II 1 year later & Occasion III 2 years later \\
\hline $\begin{array}{l}\text { Behavioral inhibition: } \\
\text { BII }\end{array}$ & Behavioral inhibition: BII & Behavioral inhibition: BII & Anxiety symptoms children: \\
& & & SCARED \\
& Parental rearing: EMBU & Parental rearing: EMBU & \\
& Trait anxiety father and mother: STAI & Trait anxiety father and mother: STAI \\
& Psychopathology children: DOMINIC & Psychopathology children: DOMINIC & \\
& Attachment: ASQ & Life events during past year: LES
\end{tabular}

$B I I$ behavioral inhibition instrument; EMBU Egna Minnen Beträffende Uppfostran, which is Swedish for My memories of upbringing; STAI state trait anxiety inventory; $A S Q$ attachment style questionnaire; LES life experiences survey; SCARED screen for child anxiety related emotional disorders; DOMINIC questionnaire to assess symptoms of 7 prevalent DSM-III-R disorders in children

comparable in terms of gender distribution [inhibited group: 58 boys and 66 girls versus control group: 57 boys and 80 girls; $\left.\chi^{2}(1)=.55, p=.46\right]$ and age [in both groups: children's age ranged between 5 and 8 , with a mean of 6.6 years; $t(258)=.55, p=.58]$. The percentages of families with a low, middle, or high socio-economic background (classified by means of the occupational levels of both parents, employing the guidelines provided by the Dutch Central Bureau of Statistics) were 15, 20, and 65\%, respectively. The majority of the children and their parents were Caucasian (97\%). The remaining families (3\%) had a Mediterranean, Asian, or North-African background. About $90 \%$ of the children came from two-parent families. During the course of the study, only 14 children dropped out. In Table 1, various assessment occasions of this longitudinal project are shown as well as the specific assessment instruments that were administered on each point-in-time.

On occasion I, children were visited by a research assistant at their schools. They were given a structured interview for measuring psychopathological symptoms. Following this, children participated in a behavioral observation procedure: children were confronted with novel stimuli and unknown persons, and their behavior was coded in terms of behavioral inhibition characteristics (for a detailed description and the results obtained with this procedure: see Van Brakel et al. 2004). Parents were sent an envelope containing questionnaires to assess their child's level of behavioral inhibition and psychopathological symptoms, their own rearing behaviors and level of trait anxiety. On occasion II, 1 year later, children were revisited at school by a research assistant who administered a structured interview to measure psychopathological symptoms. Again, parents were sent questionnaires for measuring behavioral inhibition and psychopathological symptoms of their child, parent-child attachment quality, rearing behaviors, and trait anxiety, and the number and impact of life events that had occurred during the past year. On occasion III, some 2 years later, parents as well as children were asked to complete the SCARED, a questionnaire for measuring children's anxiety symptoms in terms of the Diagnostic and Statistical Manual of Mental Disorders (DSM-IV; American Psychiatric Association 1994). A detailed description of all questionnaires and interviews will follow in the next section.

\section{Measures}

Inspired by the work of Gest (1997), Muris et al. (1999) developed the Behavioral Inhibition Instrument (BII). The BII is a brief questionnaire for assessing behavioral inhibition, which consists of two parts: (1) the Behavioral Inhibition Scale (BIS) and (2) the Behavioral Inhibition (BI) categories. The parent version of the BIS contains 8 items referring to children's shyness, fearfulness, and communication with unfamiliar people (e.g., "My child talks easily to an unfamiliar child", "My child feels nervous when he/she has to talk to an unfamiliar adult"; see also Van Brakel et al. 2004). Each item is scored on a 4-point Likert scale with $1=$ never, 2 =sometimes, $3=$ often, and $4=$ always. After recoding the positive items, scores are summed to yield a total BIS score, ranging from 8 (not apprehensive, not shy and very sociable when meeting unfamiliar persons) to 32 (very apprehensive and shy and not capable of initiating social interaction with unfamiliar persons). The BI categories are three descriptions concerning children's behavior in situations with unfamiliar people. Parents are provided with these descriptions and instructed to choose the description that applies best to their child (e.g., high behavioral inhibition = "As long as I remember, my child is shy when he/she has to talk to an unfamiliar person. On such occasions, he/she is nervous, he/she is not able to laugh, and he/she does not know what to say"). Note that the BII only contains items referring to social behavioral inhibition. In the current study, the children were qualified as inhibited when their BIS total score was higher than 22 or when their 
parents chose the description of high behavioral inhibition on the BI categories. Control children's BIS scores were 12,13 , or 14 and these children were never identified as high on behavioral inhibition on the BI categories. Previous research has yielded support for the reliability and validity of the BIS. To begin with, in a recent study by Van Brakel et al. (2004), moderate but significant relations were found between parent reports of behavioral inhibition as measured by the BIS and an observational index of this temperamental trait, thus providing evidence for the validity of the scale. Further, an investigation by Muris et al. (2003) has shown that parent ratings on the BIS had acceptable correlations with children's self-reported BIS scores ( $r$ 's between 0.44 and 0.49 ). Finally, the reliability of the BIS appears good: Cronbach's alphas are well above 0.80 , and the test-retest correlation is 0.77 when measured over a 2-year period (see Van Brakel and Muris 2006).

The Attachment Style Questionnaire (ASQ; Hazan and Shaver 1987) consists of three descriptions concerning children's feelings about and perceptions of their relationships with other children. Parents are provided with these descriptions and instructed to choose the description that applies best to their child. In this way, they classify their children as either securely, avoidantly, or ambivalently attached. In the present study, ASQ scores were dichotomized: that is, secure attachment was recoded as 0 , whereas avoidant and ambivalent attachment were both recoded as 1 (insecure attachment). In a study by Muris et al. (2001), the connection between the child version of the ASQ and a concurrent measure of attachment, the Inventory of Parent and Peer Attachment (IPPA; Armsden and Greenberg 1987), was examined. Results showed that adolescents who classified themselves as securely attached on the ASQ displayed a higher quality of attachment to both parents and peers than adolescents who classified themselves as insecurely (i.e., avoidantly or ambivalently) attached on the AQ. Clearly, this finding supports the validity of the ASQ (see also Muris and Meesters 2002).

The Modified EMBU (Egna Minnen Beträffende Uppfostran, which is Swedish for My memories of upbringing; Castro et al. 1993; Muris et al. 2003) consists of 40 items that can be allocated to four types of parental rearing: emotional warmth, rejection, overprotection, and anxious rearing. On the parent version of this scale, parents provide an indication of their own rearing behaviors. Each item is scored on a 4-point Likert scale: $1=$ No, never, $2=$ Yes, but seldom, $3=$ Yes, often, $4=$ Yes, most of the time. The psychometrics of the modified EMBU were tested in a large sample of children and adolescents $(N=1702)$. Results showed that the scale has a clear-cut 4-factor structure, which is in correspondence with the hypothesized subscales. Furthermore, EMBU scales were reliable in terms of internal consistency and test-retest stability (Muris et al. 2003). In the current study only two EMBU subscales were used, namely overprotection (e.g., "When your child comes home, he/she has to tell you what he/she has been doing") and anxious rearing (e.g., "You are scared when your child does something on his/her own"), as these seem most relevant in relation to anxiety symptoms.

The Screen for Child Anxiety Related Emotional Disorders (SCARED; Birmaher et al. 1997) is a questionnaire that attempts to measure childhood anxiety symptoms in terms of the DSM-IV. Item examples are "My child worries about things working out for him/her" (generalized anxiety disorder), "My child doesn't like being away from his/her family" (separation anxiety disorder), "When my child is frightened, his/her heart beats fast" (panic disorder). Parents have to indicate how frequently they think their child experiences each symptom on a 3-point scale: $0=$ almost never, $1=$ sometimes, and $2=$ often. SCARED total and subscale scores can be obtained by summing across relevant items. In the current study, we were particularly interested in two scores. These scores indicated the distinction between social anxiety (the sum of items referring to social phobia) and anxiety problems in general (the sum of all other items). Previous research has demonstrated that the SCARED has good internal consistency (e.g., Birmaher et al. 1997; Muris et al. 2000), test-retest reliability, and discriminant validity (e.g., Birmaher et al. 1997). Furthermore, a recent study by Muris et al. (2004) has demonstrated that SCARED scores have considerable potential for predicting specific DSMdefined anxiety disorders in non-clinical and clinically referred children and adolescents.

The Life Experiences Survey (LES; Sarason et al. 1978) is originally a 57 -item measure that allows respondents to indicate events that they have experienced during the past year. Subjects are asked to indicate those negative and positive events experienced during the past year as well as the perceived impact of each particular event. The current study only focused on negative life experiences. In other words, this measure asked parents which negative events had occurred in the life of their child during the past year, and to indicate the perceived impact of that event on a 3 -point scale with $1=a$ little stress, $2=$ average stress, and $3=a$ lot of stress. A total stress score was obtained by summing stress levels across experienced items. The original version of the LES has satisfactory psychometric properties (Sarason et al. 1978).

The Dominic-R (Valla et al. 1997) is a pictorial, fully structured questionnaire to assess symptoms of 7 prevalent DSM-III-R (American Psychiatric Association 1987) disorders in children: attention-deficit hyperactivity disorder (ADHD), oppositional defiant disorder (ODD), conduct disorder (CD), major depressive disorder (MDD), separation anxiety disorder (SAD), overanxious disorder (OAD), 
and simple phobia ( $\mathrm{SPh})$. In the present study, we were particularly interested in social phobia (SOC), and so we added 8 items to cover the symptoms of this anxiety disorder. The Dominic-R can be reliably administered by lay interviewers (Valla et al. 2000). Items (e.g., "Do you feel sick when your parents leave without you, just like Dominic?", "Are you afraid of meeting unfamiliar people, just like Dominic?") have to be answered on a yes/no scale $($ no $=0$, yes $=1)$. For each Dominic-R subscale a score can be obtained by summing across relevant items. Again the distinction between social anxiety (the sum of items referring to social phobia) and anxiety problems in general (the sum of items referring to the other anxiety scales) had our special interest. Valla et al. (2000) report that the testretest reliability of the Dominic-R and the criterion validity against clinical judgment are adequate. In the present study we employed a parent version of the Dominic-R, which means that all questionnaire items were rephrased in terms of the parents' perspective (e.g. "Does your child worry a lot about not having friends?").

The Dutch translation of the Spielberger State-Trait Anxiety Inventory (STAI; Spielberger et al. 1970; Van der Ploeg et al. 1979) was used to assess trait anxiety in the parents. This scale consists of 20 statements (e.g., "I feel tense and restless") of which subjects have to indicate the frequency on a 4-point scale: $1=$ almost never, $2=$ sometimes, $3=$ often, $4=$ almost always. The reliability and validity of the Dutch translation of the STAI have shown to be as good as the original form (Spielberger et al. 1983).

\section{Statistical Analysis}

The Statistical Package for Social Sciences (SPSS) was used for computing descriptive statistics, correlation coefficients and carrying out $t$-tests. Path analysis was used to examine whether (a) behavioral inhibition would be predictive of anxiety symptoms, especially social anxiety symptoms, from one to another point-in-time, (b) behaviorally inhibited children who experienced high levels of stress as a result of adverse life events would be particularly prone to display an increase of anxious symptoms, (c) insecure attachment, an anxious and overprotective parenting style, and parental anxiety would play a unique role in the development of children's anxious symptoms, and (d) these vulnerability factors interacted with behavioral inhibition.

Path analysis was carried out using LISREL package 8.54 (Jöreskog and Sörbom, 1993). All the variables used in the path models were first examined by means of a missing value analysis (SPSS 14.0.2). Subjects with more than 6 missing variables were excluded from further analysis. The missing values from the subjects with 1 to 6 missing variables were predicted using the linear regression analysis with residuals estimation adjustment of SPSS.
Fifty-six subjects were excluded on the basis of the abovementioned criterion, which means that 206 subjects ( 88 behavioral inhibited children and 118 controls) were used in the final data analysis. The following goodness-offit statistics were used: the Standardized Root Mean Squared Residual (SRMR) which should be 0.08 or smaller, and the Comparative Fit Index (CFI) which should be larger than 0.90 in order to have a relatively good fit between the hypothesized model and the observed data (Hu and Bentler 1999).

The strategy used for the structural equation modeling analyses of the comprehensive longitudinal model was as follows. First, all variables measured across relevant occasions were entered in the model in order to study the unique main effects of various risk factors on symptom scores. Secondly, all theoretically meaningful interaction effects were added to the model. It is important to note that a parsimonious model was construed that retained the significant main and interaction effects of various risk factors on the main outcome variables under study. Thus, the final model only included the significant paths that were obtained with the path analyses described above. The covariances between the dependent variables were set free during the analysis.

\section{Results}

\section{General Findings}

Before addressing the main issues of the current study, a number of general findings are briefly discussed. First, as can be seen in Table 2, all questionnaires were reliable in terms of internal consistency, with Cronbach's alphas ranging between 0.82 and 0.96 . Second, $t$-tests revealed that there was one significant gender difference: on occasion II, boys displayed higher social phobia scores than girls, means being $1.7(\mathrm{SD}=2.1)$ vs. $1.2(\mathrm{SD}=1.6)$ $[t(217)=2.39, p<0.001]$.

\section{Correlational Analyses}

Table 3 presents the relationships among behavioral inhibition, parental rearing, and parental anxiety on occasion I, and behavioral inhibition, social anxiety, other anxiety disorders, depression, and externalizing problems on occasion II. Only the most important relationships will be discussed here. First of all, results demonstrate that the BIS scores were stable over a 1-year period, with a test-retest correlation of 0.87 . Second, the correlation between behavioral inhibition and social anxiety was as anticipated $(r=0.71)$. Behavioral inhibition was also associated with other anxiety disorder symptoms $(r=0.28)$, although it 
Table 2 Mean scores (standard deviations) and Cronbach's alphas for all questionnaires that were used in the current study

\begin{tabular}{lcl}
\hline & $M(\mathrm{SD})$ & $\alpha$ \\
\hline Screening & $18.9(6.6)$ & 0.91 \\
BII & & \\
Occasion I & $17.7(6.3)$ & 0.96 \\
BII & $14.8(9.8)$ & 0.89 \\
DOMINIC & $43.9(6.2)$ & 0.82 \\
EMBU & $35.1(8.9)$ & 0.91 \\
STAI mother & $32.2(9.0)$ & 0.93 \\
STAI father & & \\
Occasion II & $16.9(6.3)$ & 0.96 \\
BII & $13.8(10.3)$ & 0.89 \\
DOMINIC & $42.7(6.5)$ & 0.83 \\
EMBU & $33.6(8.9)$ & 0.93 \\
STAI mother & $31.8(8.1)$ & 0.92 \\
STAI father & $37(15.9)^{\mathrm{a}}$ & $\mathrm{b}$ \\
ASQ insecure & $2.6(3.0)$ & $\mathrm{b}$ \\
LES & & 0.95 \\
Occasion III & $26.6(19.0)$ & \\
SCARED & & \\
\hline BII behavior & & \\
\hline
\end{tabular}

$B I I$ behavioral inhibition instrument; $E M B U$ Egna Minnen Beträffende Uppfostran, which is Swedish for My memories of upbringing; STAI trait version of the State-Trait Anxiety Inventory; $A S Q$ attachment style questionnaire; SCARED screen for child anxiety related emotional disorders; LES life experiences survey; DOMINIC questionnaire to assess symptoms of 7 prevalent DSM-III$\mathrm{R}$ disorders in children

$N=261$

a Attachment was measured by means of a 1-item measure: The number (percentage) of children classified as insecurely attached is shown

b Cronbach's alpha could not be computed for these measures

should be mentioned that the correlation between behavioral inhibition and social anxiety was significantly larger than the correlation between behavioral inhibition and other anxiety disorder symptoms $(Z=7.70, p<0.001)$. Behavioral inhibition was significantly related to symptoms of depression $(r=-0.21)$, but did not show a significant association with externalizing problems $(r=$ $-0.02)$. Third, the results indicate that the other risk factors that were assessed on occasion I were also related to anxiety and other psychopathological symptoms as measured on occasion II. More specifically, anxious rearing not only showed a significant correlation with other anxiety disorders $(r=0.39)$, but also with depression and externalizing problems ( $r$ 's being 0.37 and 0.41 , respectively). Further, in particular trait anxiety of the mother was related to behavioral inhibition and all psychopathology measures on occasion II ( $r$ 's ranging between 0.21 and 0.39 ).

Table 4 displays the relationships between behavioral inhibition, parental rearing, attachment, parental anxiety, and life events on occasion II and social anxiety and other anxiety disorder symptoms as measured by the SCARED, on occasion III. Note that, behavioral inhibition on occasion II was related to both social anxiety and other anxiety disorder symptoms on occasion III ( $r$ 's being 0.72 and 0.34 respectively), with the former being again stronger than the latter correlation $(Z=8.84, p<0.001)$. In addition, other risk factors measured on occasion II (anxious rearing, attachment, parental anxiety, and life experiences) also showed significant correlations with social anxiety as well as with symptoms of other anxiety disorders on occasion III ( $r$ 's ranging between 0.13 and 0.35 ).

The correlations between behavioral inhibition, parental rearing, and parental anxiety on occasion I, and symptoms of social anxiety and other anxiety disorders as measured by the SCARED on occasion III are shown in Table 5. The results show that behavioral inhibition on occasion I was strongly linked to social phobia and, to a lesser extent, to other anxiety disorders some 3 years later ( $r$ 's being 0.66 and 0.29 respectively; $Z=8.13, p<0.001$ ). Second, some of the other risk factors also had long-term relationships with anxiety symptoms. More precisely, anxious rearing was significantly related to other anxiety disorders $(r=0.26)$, whereas trait anxiety of the mother was connected to symptoms of social phobia $(r=0.32)$ as well as other anxiety disorders $(r=0.32)$.

\section{Structural Equation Modeling}

Figure 1 shows the path model that examined the specificity of behavioral inhibition in predicting symptoms of anxiety disorders and in particular social anxiety as well as other psychopathological symptoms (i.e., from occasion I to II). As can be seen in this figure, behavioral inhibition predicted social anxiety, but failed to predict other anxiety disorder symptoms, depression, or externalizing problems. The fit indices for this model were reasonable $(\mathrm{CFI}=0.89$; SRMR $=0.10$ ), and so it can be concluded that behavioral inhibition only acted as a specific risk factor for the development of social anxiety.

Figure 2 shows the path analysis examining the influence of behavioral inhibition in interaction with life events on the development of social anxiety, other anxiety disorder symptoms, and depression in children during a 1-year period (i.e., from occasion I to occassion II). The final model was found to have an acceptable fit $(\mathrm{CFI}=0.90 ; \mathrm{SRMR}=0.07)$. Note that no moderating effects of 'life events' on the link between behavioral inhibition and any of the anxiety/psychopathology scores were found. That is, 'life events' did not interact with behavioral inhibition, but rather acted as an independent factor influencing the development of other anxiety disorders and depression. 
Table 3 Correlations between behavioral inhibition, parental rearing, and parental anxiety on occasion I, and behavioral inhibition, social anxiety, other anxiety disorders, depression, and externalizing problems on occasion II

\begin{tabular}{|c|c|c|c|c|c|}
\hline & \multicolumn{5}{|l|}{ Occasion II } \\
\hline & \multirow{2}{*}{$\begin{array}{l}\text { BII } \\
\text { Behavioral } \\
\text { inhibition }\end{array}$} & \multicolumn{4}{|l|}{ DOMINIC } \\
\hline & & Social anxiety & $\begin{array}{l}\text { Other anxiety } \\
\text { disorders }\end{array}$ & Depression & $\begin{array}{l}\text { Externalizing } \\
\text { problems }\end{array}$ \\
\hline \multicolumn{6}{|l|}{ Occasion I } \\
\hline BII & $0.87 * *$ & $0.71 * *$ & $0.28 * *$ & $0.21 *$ & -0.02 \\
\hline \multicolumn{6}{|l|}{$E M B U$} \\
\hline Anxious rearing & 0.07 & 0.10 & $0.39 * *$ & $0.37 * *$ & $0.41 * *$ \\
\hline Overprotection & 0.00 & -0.03 & 0.07 & 0.11 & $0.13 *$ \\
\hline \multicolumn{6}{|l|}{ STAI } \\
\hline Mother & $0.23 * *$ & $0.21 * *$ & $0.26 * *$ & $0.34 * *$ & $0.39 * *$ \\
\hline Father & 0.07 & 0.12 & 0.10 & 0.11 & $0.18 *$ \\
\hline
\end{tabular}

$* p<0.05, * * p<0.01$

$B I I$ behavioral inhibition instrument; EMBU Egna Minnen Beträffende Uppfostran, which is Swedish for My memories of upbringing; STAI trait version of the State-Trait Anxiety Inventory; DOMINIC questionnaire to assess symptoms of 7 prevalent DSM-III-R disorders in children $N=261$

Table 4 Correlations between behavioral inhibition, parental rearing, attachment, parental anxiety, and life events on occasion II, and social anxiety and other anxiety disorder symptoms on occasion III

\begin{tabular}{|c|c|c|}
\hline & \multicolumn{2}{|l|}{ Occasion III } \\
\hline & SCARED social anxiety & SCARED other anxiety disorders \\
\hline \multicolumn{3}{|l|}{ Occasion II } \\
\hline BII & $0.72 * *$ & $0.34 * *$ \\
\hline \multicolumn{3}{|l|}{$E M B U$} \\
\hline Anxious Rearing & $0.13^{*}$ & $0.23 * *$ \\
\hline Overprotection & -0.10 & -0.04 \\
\hline \multicolumn{3}{|l|}{$A S Q$} \\
\hline Attachment & $0.35^{* *}$ & $0.28 * *$ \\
\hline \multicolumn{3}{|l|}{ STAI } \\
\hline Mother & $0.33 * *$ & $0.33 * *$ \\
\hline Father & $0.13 *$ & $0.20 * *$ \\
\hline \multicolumn{3}{|l|}{ LES } \\
\hline Life experiences & $0.19 * *$ & $0.33 * *$ \\
\hline
\end{tabular}

$* p<0.05, * * p<0.01$

$B I I$ behavioral inhibition instrument; EMBU Egna Minnen Beträffende Uppfostran, which is Swedish for My memories of upbringing; STAI trait version of the State-Trait Anxiety Inventory; $A S Q$ attachment style questionnaire; LES life experiences survey, SCARED screen for child anxiety related emotional disorders

$N=261$

Figure 3 (the final model only included the significant paths that were obtained with the path analyses described above) shows the best fitting model (CFI $=0.89$; SRMR $=0.06$ ) of the direct and moderating paths reflecting the influence of various risk factors on children's level of social anxiety and other anxiety disorder symptoms during the entire 3-year follow-up period. Note that across all occasions behavioral inhibition, social anxiety, and other anxiety disorder symptoms remained fairly stable (all beta's between 0.31 and 0.88). Most importantly, it was found that behavioral inhibition on occasion I had a unique effect in predicting social phobia on occasion II (beta $=0.28$ ), whereas behavioral inhibition on occasion II had a independent influence on social phobia and other anxiety disorders on occasion III (beta $=$ respectively 0.45 and 0.12). Of course, these findings underline the role of 
Table 5 Correlations between behavioral inhibition, parental rearing and parental anxiety on occasion I and social anxiety and other anxiety disorder symptoms on occasion III

\section{Occasion III}

SCARED social anxiety

SCARED other anxiety disorders

Occasion I

$0.66 * * \quad 0.29 * *$

$E M B U$

$\begin{array}{lll}\text { Anxious Rearing } & 0.11 & 0.26^{* * *}\end{array}$

$\begin{array}{lll}\text { Overprotection } & -0.04 & 0.05\end{array}$

STAI

$\begin{array}{lll}\text { Mother } & 0.32 * * & 0.32 * *\end{array}$

$\begin{array}{lll}\text { Father } & 0.03 & 0.08\end{array}$

$* p<0.05, * * p<0.01$

$B I I$ behavioral inhibition instrument; EMBU Egna Minnen Beträffende Uppfostran, which is Swedish for My memories of upbringing; STAI trait version of the State-Trait Anxiety Inventory; SCARED screen for child anxiety related emotional disorders

$N=261$

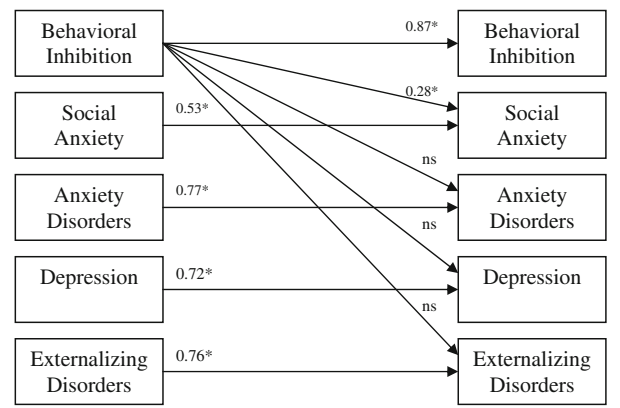

Fig. 1 Results of the path analysis examining the specificity of behavioral inhibition in predicting symptoms of anxiety disorders and in particular social anxiety as well as other psychopathological symptoms from occasion I to II. Note. Path coefficients represent standardized beta estimates. $* p<0.05$ level. Comparative Fit Index $(\mathrm{CFI})=0.89$ and $\mathrm{SRMR}=0.10$

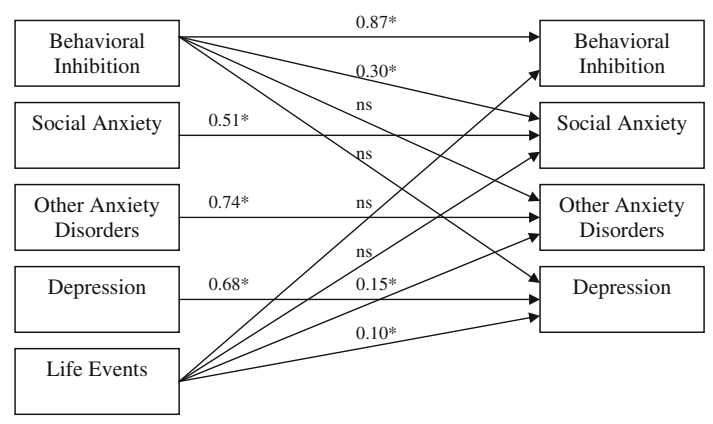

Fig. 2 Results of the path analysis examining the influence of behavioral inhibition, life events, and their interaction on the development of social anxiety, other anxiety disorder symptoms, and depression in children during a 1-year period (i.e., from occasion I to II). Note. No moderating effect of 'life events' on the relation between behavioral inhibition and anxiety and depression symptoms was found. Path coefficients represent standardized beta estimates. $* p<0.05$ level. Comparative Fit Index $(\mathrm{CFI})=0.90$ and SRMR $=0.07$ behavioral inhibition in the development of childhood anxiety symptoms and in particular symptoms of social phobia.

Note further that a number of risk factors made significant additional contributions. For example, parental rearing style predicted behavioral inhibition and some of the psychopathological symptoms in this model. That is, overprotection on occasion I had a small but unique effect on behavioral inhibition on occasion II (beta $=0.10$ ), while anxious rearing on occasion I significantly predicted symptoms of other anxiety disorders on occasion II (beta $=0.12$ ). In addition, trait anxiety of mother and father as measured on occasion II, each uniquely predicted anxiety symptoms on occasion III. More precisely, a significant path emerged between trait anxiety of the father on occasion II and other anxiety disorders on occasion III (beta $=0.12$ ) as well as between trait anxiety of the mother on occasion II and social phobia/other anxiety disorders on the last occasion (beta's being 0.14 and 0.13 ).

Only two significant interaction effects were found. To begin with, behavioral inhibition and trait anxiety of the father on occasion I had an interactive effect on behavioral inhibition on occasion II (beta $=0.43$ ), which indicated that high behavioral inhibited children with an anxious father displayed the highest behavioral inhibition levels on occasion II. Second, behavioral inhibition and attachment on occasion II had an interactive effect on other anxiety disorders on occasion III (beta $=0.59$ ). That is, children who were defined as high on behavioral inhibition and insecurely attached displayed the highest levels of anxiety symptoms over time, whereas children who were classified as low on inhibition and securely attached on occasion II exhibited the lowest anxiety levels. 


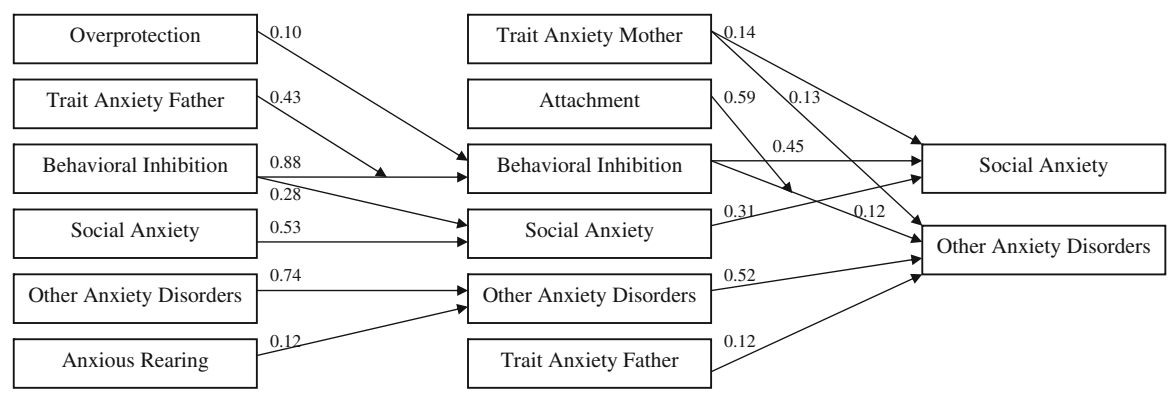

Fig. 3 Results of the path analysis testing direct and moderating paths of various risk factors on the development of social anxiety and other anxiety disorder symptoms in children during the 3-year followup period. Note. Path coefficients represent standardized beta

\section{Discussion}

The present study examined the additive and interactive effects of behavioral inhibition and other risk factors on the development of childhood anxiety symptoms using a longitudinal research design. Moreover, it was investigated whether behavioral inhibition plays a role in the development of social anxiety, anxiety problems in general, or a broad range of psychopathological symptoms. The main results of the study can be summarized as follows. Consistent with the hypothesis that behavioral inhibition is a rather specific vulnerability factor, the results indicated that high levels of this temperamental factor were particularly associated with an increase of social anxiety symptoms over time. The longitudinal associations between behavioral inhibition and other anxiety problems were clearly less strong, whereas prospective connections with other psychopathological symptoms were not found. Thus, the current findings seem to justify the conclusion that behavioral inhibition primarily acts as a specific risk factor for the development of social anxiety symptoms (see Hirshfeld-Becker et al. 2008a).

Second, the current study demonstrated that besides behavioral inhibition, a number of other risk factors made significant additional contributions in the model explaining anxiety symptoms across the three-year period. For example, anxious rearing on occasion I significantly predicted symptoms of other anxiety disorders on occasion II (see for comparable results Grüner et al. 1999; Muris et al. 2000, 2003), whereas trait anxiety of both parents as measured on occasion II made independent contributions to anxiety symptoms on occasion III. The latter finding is in line with a study of Biederman et al. (1991) who showed that children of high anxious parents run a greater risk for developing anxiety disorders themselves.

Further, some evidence emerged showing that risk factors interacted with each other, thereby creating an increased vulnerability for developing anxiety. That is, behavioral inhibition and attachment on occasion II had an interactive estimates. All of the path coefficients are significant beyond the $p<0.05$ level. Comparative Fit Index $(\mathrm{CFI})=0.89$ and SRMR $=$ 0.06

effect on other anxiety disorders on occasion III. That is, children who were defined as high on behavioral inhibition and insecurely attached displayed the highest levels of anxiety symptoms over time, whereas children who were classified as low on inhibition and securely attached on occasion II exhibited the lowest anxiety levels. This result adds to earlier studies showing that children who combine a behaviorally inhibited temperament with an insecure attachment status tend to display the highest levels of anxiety disorders symptoms (e.g., Calkins and Fox 1992; Mannasis et al. 1995; Muris and Meesters 2002; Shamir-Essakow et al. 2005), which shows that individual risk factors may influence each other, thereby yielding an even greater risk for the development of anxiety pathology in youths.

Moreover, the final model showed that not only anxiety symptoms were predicted by various risk factors, behavioral inhibition itself was also influenced by some of the vulnerability factors. That is, overprotection on occasion I had a small but unique effect on behavioral inhibition on occasion II. Further, behavioral inhibition and trait anxiety of the father on occasion I had an interactive effect on behavioral inhibition on occasion II, indicating that high behaviorally inhibited children with an anxious father displayed an increase of behavioral inhibition levels on occasion II. These findings are in keeping with the notion that overprotective/anxious parents may hinder their behaviorally inhibited children from developing effective coping strategies and acquiring adequate social skills (Rapee 1997), which is likely to result in avoidance of 'anxious' situations. As a consequence, these children remain inhibited or even become more inhibited (Rubin et al. 1997, 1999; Van Brakel et al. 2006; for a review see Rubin et al. 2009). Note that the current data suggest that fathers might play a specific role in this respect: if he shows high levels of anxiety, the inhibited child is particularly prone to continue or even intensify his/her temperamental vulnerability (Bögels and Phares 2007).

Finally, the current study tested the idea (consistent with a diathesis-stress framework) that behaviorally inhibited 
children who experienced high levels of stress as a result of adverse life events would be particularly prone to display an increase of anxious symptoms. This hypothesis could not be confirmed. The results showed that 'life events' did not interact with behavioral inhibition in the prediction of symptom levels, but rather acted as an independent factor influencing the development of depression and other anxiety disorders. In contrast, Brozina and Abela (2006) found that stress (as a result of adverse life events) moderated the relationship between behavioral inhibition and anxiety symptoms. That is, children with high behavioral inhibition showed increases in anxious symptoms when they experienced high levels of stress. A possible explanation for these contrasting findings could be, first of all, the length of the follow-up period (i.e., 6 weeks in the Brozina and Abela study versus 1 year in the current study). It might be possible that a period of 1 year is too long to retrospectively assess stress levels in a valid way. Second, it may well be that the children in the present study were too young to really experience the negative impact of these adverse life events. Third and finally, the measures that were used in both studies differed. That is, whereas the current investigation relied on an index listing serious but rather infrequent life events (e.g., death of a parent, financial problems, divorce of parents), Brozina and Abela employed a scale measuring daily hassles, which simply may have been more sensitive to assess children's levels of experienced stress.

Altogether, the recent findings confirm the validity of etiological models which assume that the pathogenesis of anxiety can best be conceptualized as a dynamic interplay of various predisposing factors. Vasey and Dadds (2001) and Muris (2007) have described such multifactorial frameworks for the development of childhood anxiety disorders. Of particular importance in these models are the reciprocal connections between the different risk and protective factors within a developmental context.

Several limitations of the current study should be considered when interpreting the current results. First, we did not assess diagnoses of anxiety disorders and other mental disorders (e.g., depression). Nevertheless, it should be mentioned that the SCARED which was employed as the primary outcome measure, provides a good indication of various DSM-defined anxiety disorders in non-clinical and clinically referred children and adolescents (Muris et al. 2004). Second, despite the fact that the BIS has been thoroughly investigated in previous studies (e.g., Van Brakel et al. 2004; Shatz 2005) and turned out to be a valid and reliable measure, it predominantly measures social aspects of behavioral inhibition. Although the choice for the BIS can be defended by pointing at past research indicating that the non-social aspects of behavioral inhibition are more susceptible to developmental changes than the social aspects of behavioral inhibition (Hirshfeld-
Becker et al. 2004; Van Brakel et al. 2004; Van Brakel and Muris 2006), the study would have gained in strength if we had included a measure that also covers the non-social aspects of the inhibited temperament (such as the Behavioral Inhibition Questionnaire; Bishop et al. 2003; Broeren and Muris 2010), especially since there are some indications that non-social behavioral inhibition may be a more reliable predictor of 'other anxiety disorder symptoms' (e.g., Van Brakel et al. 2004). Third, most of the data on behavioral inhibition, attachment, parental rearing and psychopathological symptoms were obtained from one and the same informant (i.e., parents). As such, it is possible that the observed associations might have been elevated due to shared method variance. Preferably, researchers should rely on multiple informants when investigating such relationships. Note, however, that the children in the current study were too young to reliably fill out these complex questionnaires. Fourth, despite the longitudinal set-up of the study, children were only followed for 3 years. Thus, it remains unclear how behavioral inhibition assessed at a young age relates to social phobia, various types of anxiety disorders, and depression over longer time periods. In this context, Brozina and Abela (2006) have pointed out that it is possible that the association between behavioral inhibition and depressive symptoms is not evident until adolescence when depressive disorders become more prevalent. In other words, it might be possible that our sample of children was too young to detect the development of certain types of problems. Fifth, according to current temperament researchers (see Muris and Ollendick 2005), vulnerability to psychopathology is not only characterized by reactive temperament features such as behavioral inhibition but also by lack of regulative traits such as effortful control. That is, high levels of behavioral inhibition make children prone to develop psychological disorders, but it may well be the case that the negative impact of this temperament variable can be buffered by effortful control. The present study mainly focused on reactive temperament (behavioral inhibition) but it may well be that 'effortful control' accounts for some of the variation in the development of anxiety symptoms within our group of behavioral inhibited children. Sixth and finally, another issue which needs attention is the possible tautological nature of the link between (social) behavioral inhibition and social anxiety. Note, however, that the current data demonstrate that even when controlling for social anxiety on previous assessment occasions, behavioral inhibition still remained a significant predictor of subsequent social anxiety symptoms.

Despite these limitations, the current data provide support for the notion that various predisposing factors have additive and, to some extent, interactive effects on the pathogenesis of anxiety in children. Further, the present 
findings suggest that behavioral inhibition should be primarily viewed as a specific risk factor for the development of social anxiety in children rather than a general vulnerability factor for a broad range of anxiety problems, although there might be clear methodological issues (i.e., age of the children, use of the BIS for measuring behavioral inhibition) that may have biased our results. Future research might address the role of reactive and regulative factors when examining the predictive value of temperament on the development of anxiety and other psychopathological symptoms in children (e.g., Calkins and Fox 1992; Muris and Ollendick 2005). In addition, more prospective studies are needed in which children are followed for longer periods of time, preferably from birth to adulthood. In this way, individual developmental trajectories could be elucidated, and clinical, cognitive, and developmental information might be further integrated in a comprehensive model on the development of childhood anxiety disorders.

Open Access This article is distributed under the terms of the Creative Commons Attribution Noncommercial License which permits any noncommercial use, distribution, and reproduction in any medium, provided the original author(s) and source are credited.

\section{References}

American Psychiatric Association. (1987). Diagnostic and statistical manual of mental disorders, 3rd edition-revised (DSM-III-R). Washington, DC: American Psychiatric Association.

American Psychiatric Association. (1994). Diagnostic and statistical manual of mental disorders (DSM-IV) (4th ed.). Washington, DC: American Psychiatric Association.

Armsden, G. C., \& Greenberg, M. T. (1987). The inventory of parent and peer attachment: Individual differences and their relationship to psychological well-being in adolescence. Journal of youth and adolescence, 16, 427-454.

Barrett, P., Rapee, R., Dadds, M. R., \& Ryan, S. M. (1996). Family enhancement of cognitive style in anxious and aggressive children: Threat bias and the FEAR effect. Journal of Abnormal Child Psychology, 24, 187-203.

Biederman, J., Rosenbaum, J. F., Bolduc, E. A., Faraone, S. V., \& Hirshfeld, D. R. (1991). A high risk study of young children of parents with panic disorder and agoraphobia with and without comorbid major depression. Journal of Psychiatric Research, 37, 333-348.

Biederman, J., Rosenbaum, J. F., Bolduc-Murphy, E. A., \& Faraone, S. V. (1993). A three year follow-up of children with and without behavioral inhibition. Journal of the American Academy of Child and Adolescent Psychiatry, 32, 814-821.

Biederman, J., Rosenbaum, J. F., Hirshfeld, D. R., Faraone, S. V., Bolduc, E. A., Gersten, M., et al. (1990). Psychiatric correlates of behavioral inhibition in young children of parents with and without psychiatric disorders. Archives of General Psychiatry, 47, 21-26.

Birmaher, B., Khetarpal, S., Brent, D., Cully, M., Balach, L., Kaufman, J., et al. (1997). The screen for child anxiety related emotional disorders (SCARED): Scale construction and psychometric characteristics. Journal of the American Academy of Child and Adolescent Psychiatry, 36, 545-553.

Bishop, G., Spence, S. H., \& McDonald, C. (2003). Can parents and teachers provide a reliable and valid report of behavioral inhibition? Child Development, 74, 1899-1917.

Bögels, S., \& Phares, V. (2007). Fathers' role in the etiology, prevention, and treatment of child anxiety: A review and new model. Clinical Psychology Review, 28, 539-558.

Broeren, S., \& Muris, P. (2010). A psychometric evaluation of the behavioral inhibition questionnaire in a non-clinical sample of Dutch children and adolescents. Child Psychiatry and Human Development, 41, 214-229.

Brozina, K., \& Abela, J. R. Z. (2006). Behavioural inhibition, anxious symptoms, and depressive symptoms: A short-term prospective examination of a diathesis-stress model. Behaviour Research and Therapy, 44, 1337-1346.

Calkins, S., \& Fox, N. (1992). The relations among infant temperament, security of attachment, and behavioral inhibition at 24 months. Child Development, 63, 1456-1472.

Castro, J., Toro, J., van der Ende, J., \& Arrindell, W. A. (1993). Exploring the feasibility of assessing perceived parental rearing styles in Spanish children with the EMBU. International Journal of Social Psychiatry, 39, 47-57.

Chronis-Tuscano, A., Degnan, K. A., Pine, D. S., Perez-Edgar, K., Henderson, H. A., Diaz, Y., et al. (2009). Stable early maternal report of behavioral inhibition predicts lifetime social anxiety disorder in adolescence. Journal of the American Academy of Child and Adolescent Psychiatry, 48, 928-935.

Essex, M. J., Klein, M. H., Slattery, M. J., Goldsmith, H. H., \& Kalin, N. H. (2010). Early risk factors and developmental pathways to chronic high inhibition and social anxiety disorder in adolescence. American Journal of Psychiatry, 167, 40-46.

Fox, N. A., Henderson, H. A., Marshall, P. J., Nichols, K. E., \& Ghera, M. M. (2005). Behavioral inhibition: Linking biology and behaviour within a developmental framework. Annual Review of Psychology, 56, 235-262.

Gest, S. D. (1997). Behavioral inhibition: Stability and associations with adaptation from childhood to early adulthood. Journal of Personality and Social Psychology, 72, 467-475.

Gladstone, G. L., \& Parker, G. B. (2006). Is behavioral inhibition a risk factor for depression? Journal of Affective Disorders, 95, 85-94.

Gladstone, G. L., Parker, G. B., Mitchell, P. B., Wilhelm, K. A., \& Mahli, G. S. (2005). Relationship between self-reported childhood behavioural inhibition and lifetime anxiety disorders in a clinical sample. Depression and Anxiety, 22, 103-113.

Grüner, K., Muris, P., \& Merckelbach, H. (1999). The relationship between anxious rearing behaviours and anxiety disorders symptomatology in normal children. Journal of Behavior Therapy and Experimental Psychiatry, 30, 27-35.

Gullone, E., Ollendick, T. H., \& King, N. J. (2006). The role of attachment representation in the relationship between depressive symptomatology and social withdrawal in middle childhood. Journal of Child and Family Studies, 15, 271-285.

Hayward, C., Killen, J. D., Kraemer, H. C., \& Taylor, C. B. (1998). Linking self-reported childhood behavioral inhibition to adolescent social phobia. Journal of the American Academy of Child and Adolescent Psychiatry, 37, 1308-1316.

Hazan, C., \& Shaver, P. (1987). Romantic love conceptualized as an attachment process. Journal of Personality and Social Psychology, 52, 511-524.

Hirshfeld-Becker, D. R., Biederman, J., Calltharp, S., Rosenbaum, E. D., Faraone, S. V., \& Rosenbaum, S. V. (2003). Behavioral inhibition and disinhibition as hypothesized precursors to psychopathology: Implications for pediatric bipolar disorder. Biological Psychiatry, 53, 985-999. 
Hirshfeld-Becker, D. R., Biederman, J., Henin, A., Faraone, S. V., Davis, S., Harrington, K., et al. (2007). Behavioral inhibition in preschool children at risk is a specific predictor of middle childhood social anxiety: A 5-year follow-up. Journal of Developmental and Behavioral Pediatrics, 28, 225-233.

Hirshfeld-Becker, D. R., Biederman, J., \& Rosenbaum, J. F. (2004). Behavioral inhibition. In T. L. Morris \& J. S. March (Eds.), Anxiety disorders in children and adolescents (2nd ed., pp. 2758). New York: Guilford Press.

Hirshfeld-Becker, D. R., Micco, J., Henin, A., Bloomfield, A., Biederman, J., \& Rosenbaum, J. (2008a). Behavioral inhibition. Depression and Anxiety, 25, 357-367.

Hirshfeld-Becker, D. R., Micco, J., Simoes, N. A., \& Henin, A. (2008b). High risk studies and developmental antecedents of anxiety disorders. American Journal of Medical Genetics, 148C, 99-117.

Hirshfeld-Becker, D. R., Rosenbaum, J. F., Biederman, J. F., Bolduc, E. A., Faraone, S. V., Snidman, N., et al. (1992). Stable behavioral inhibition and its association with anxiety disorder. Journal of the American Academy of Child and Adolescent Psychiatry, 31, 103-111.

Hu, L., \& Bentler, P. M. (1999). Cutoff criteria for fit indexes in covariance structure analysis: Conventional criteria versus new alternatives. Structural Equation Modeling, 6, 1-55.

Hudson, J. L., \& Rapee, R. M. (2001). Parent-child interactions and anxiety disorders: An observational study. Behaviour Research and Therapy, 39, 1411-1427.

Jaffee, S. R., Moffitt, T. E., Caspi, A., Fombonne, E. P. R., \& Martin, J. (2002). Differences in early childhood risk factors for juvenileonset and adult-onset depression. Archives of General Psychiatry, 59, 215-222.

Jöreskog, K., \& Sörbom, D. (1993). LISREL 8: Structural equation modelling with the SIMPLIS command language. Hillsdale, $\mathrm{NJ}$ : Lawrence Erlbaum.

Kagan, J. (1994). Galen's prophecy: Temperament in human nature. New York: Basic Books.

Kagan, J., Reznick, J. S., \& Snidman, N. (1988). Biological bases of childhood shyness. Science, 240, 167-171.

Mannasis, K., Bradley, S., Goldberg, S., Hood, J., \& Swinson, R. P. (1995). Behavioural inhibition, attachment and anxiety in children of mothers with anxiety disorders. Canadian Journal of Psychiatry, 40, 87-92.

Mick, M. A., \& Telch, M. J. (1998). Social anxiety and history of behavioral inhibition in young adults. Journal of Anxiety Disorders, 12, 1-20.

Muris, P. (2007). Normal and abnormal fear and anxiety in children and adolescents. Oxford: Elsevier.

Muris, P., Bos, A. E. R., Mayer, B., Verkade, R., Thewissen, V., \& Dell'Avvento, V. (2009). Relations among behavioral inhibition, big five personality factors, and anxiety disorder symptoms in non-clinical children. Personality and Individual Differences, $46,525-529$.

Muris, P., Dreessen, L., Bögels, S. M., Weckx, M., \& Van Melick, M. (2004). A questionnaire for screening a broad range of DSMdefined anxiety disorder symptoms in clinically referred children and adolescents. Journal of Child Psychology and Psychiatry, $45,813-820$.

Muris, P., \& Meesters, C. (2002). Attachment, behavioral inhibition, and anxiety disorders symptoms in normal adolescents. Journal of Psychopathology and Behavioral Assessment, 24, 97-105.

Muris, P., Meesters, C., Merckelbach, H., \& Hülsenbeck, P. (2000a). Worry in children is related to perceived parental rearing and attachment. Behavior Research and Therapy, 38, 487-497.

Muris, P., Meesters, C., \& Spinder, M. (2003a). Relationships between child- and parent-reported behavioural inhibition and symptoms of anxiety and depression in normal adolescents. Personality and Individual Differences, 34, 759-771.

Muris, P., Meesters, C., \& Van Brakel, A. (2003b). Assessment of anxious Rearing Behaviors with a modified version of "Egna Minnen Beträffande Uppfostran" questionnaire for children. Journal of Psychopathology and Behavioral Assessment, 25, 229-237.

Muris, P., Meesters, C., Van Melick, M., \& Zwambag, L. (2001a). Self-reported attachment style, attachment quality, and symptoms of anxiety and depression in young adolescents. Personality and Individual Differences, 30, 809-818.

Muris, P., Merckelbach, H., Schmidt, H., Gadet, B., \& Bogie, N. (2001b). Anxiety and depression as correlates of self-reported behavioral inhibition in normal adolescents. Behaviour Research and Therapy, 39, 1051-1061.

Muris, P., Merckelbach, H., Wessel, I., \& Van de Ven, M. (1999). Psychopathological correlates of self-reported behavioral inhibition in normal children. Behaviour Research and Therapy, 37, $575-584$.

Muris, P., \& Ollendick, T. H. (2005). The role of temperament in the etiology of child psychopathology. Clinical Child and Family Psychology Review, 8, 271-289.

Muris, P., Schmidt, H., \& Merckelbach, H. (2000b). Correlations among two self-report questionnaires for measuring DSMdefined anxiety disorder symptoms in children: The screen for child anxiety related emotional disorders and the spence children's anxiety scale. Personality and Individual Differences, 28, 333-346.

Rapee, R. M. (1997). Potential role of childrearing practices in the development of anxiety and depression. Clinical Psychology Review, 17, 47-67.

Rapee, R. M., Schniering, C. A., \& Hudson, J. L. (2009). Anxiety disorders during childhood and adolescence. Annual Review of Clinical Psychology, 5, 311-341.

Reznick, J. S., Hegeman, I. M., Kaufman, E., Woods, S. W., \& Jacobs, M. (1992). Retrospective and concurrent self-report of behavioral inhibition and their relation to adult mental health. Developmental Psychology, 4, 301-321.

Rosenbaum, J. F., Biederman, J., Bolduc, E. A., Hirshfeld, D. R., Faraone, S. V., \& Kagan, J. (1992). Comorbidity of parental anxiety disorders as risk for childhood-onset anxiety in inhibited children. American Journal of Psychiatry, 149, 475-481.

Rosenbaum, J. F., Biederman, J., Gersten, M., Hirshfeld, D. R., Meminger, S. R., Herman, J. B., et al. (1988). Behavioral inhibition in children of parents with panic disorder and agoraphobia: A controlled study. Archives of General Psychiatry, 45, 463-470.

Rubin, K. H., Coplan, R. J., \& Bowker, J. C. (2009). Social withdrawal in childhood. Annual Review of Psychology, 60, 141-171.

Rubin, K. H., Hastings, P. D., Stewart, S. L., Henderson, H. A., \& Chen, X. (1997). The consistency and concomitants of inhibition: Some of the children, all of the time. Child Development, 68, 467-483.

Rubin, K. H., Nelson, L. J., Hastings, P., \& Asendorpf, J. (1999). The transaction between parents' perceptions of their children's shyness and their parenting styles. International Journal of Behavioral Development, 23, 937-957.

Sarason, I. G., Johnson, J. H., \& Siegel, J. M. (1978). Assessing the impact of life changes: Development of the life experiences survey. Journal of Consulting and Clinical Psychology, 46, 932946.

Shamir-Essakow, G., Ungerer, J. A., \& Rapee, R. M. (2005). Attachment, behavioral inhibition, and anxiety in preschool children. Journal of Abnormal Child Psychology, 33, 131-143. 
Shatz, S. M. (2005). The psychometric properties of the behavioral inhibition scale in a college-aged sample. Personality and Individual Differences, 39, 331-339.

Spielberger, C. D., Gorsuch, R. L., \& Lushene, R. E. (1970). STAI manual for the state-trait inventory. Palo Alto, California: Consulting Psychologists Press.

Spielberger, C. D., Gorsuch, R. L., Lushene, R. E., Vagg, R. E., \& Jacobs, G. A. (1983). Manual for the State-Trait Anxiety Inventory. Palo Alto, California: Consulting Psychologists Press.

Tiet, Q. Q., Bird, H. R., Hoven, C. W., Moore, R., Wu, P., Wicks, J., et al. (2001). Relationship between specific adverse life events and psychiatric disorders. Journal of Abnormal Child Psychology, 29, 153-164.

Townsley-Stemberger, R., Turner, S. M., Beidel, C. C., \& Calhoun, K. S. (1995). Social phobia: An analysis of possible developmental factors. Journal of Abnormal Psychology, 104, 526-531.

Turner, S. M., Beidel, D. C., \& Wolff, P. L. (1996). Is behavioral inhibition related to the anxiety disorders? Clinical Psychology Review, 16, 157-172.

Valla, J. P., Bergeron, L., Bidaut-Rusell, M., St-Georges, M., \& Gaudet, M. (1997). Reliability of the Dominic-R: A young child mental health questionnaire combining visual and auditory stimuli. Journal of Child Psychology and Psychiatry, 38, 717724.

Valla, J. P., Bergeron, L., \& Smolla, N. (2000). The Dominic-R: A pictorial interview for 6- to 11-year old children. Journal of the American Academy for Child and Adolescent Psychiatry, 39, 85-93.

Van Brakel, A. M. L., \& Muris, P. (2006). A brief scale for measuring "behavioral inhibition to the unfamiliar" in children. Journal of Psychopathology and Behavioral Assessment, 28, 79-84.
Van Brakel, A. M. L., Muris, P., \& Bögels, S. M. (2004). Relations between parent- and teacher-reported behavioral inhibition and behavioral observations of this temperamental trait. Journal of Clinical Child and Adolescent Psychology, 33, 579-589.

Van Brakel, A. M. L., Muris, P., Bögels, S. M., \& Thomassen, C. (2006). A multifactorial model for the etiology of anxiety in nonclinical adolescents: Main and interactive effects of behavioral inhibition, attachment, and parental rearing. Journal of Child and Family Studies, 15, 568-578.

Van der Ploeg, H. M., Defares, P. B., \& Spielberger, C. D. (1979). Een Nederlandstalige bewerking van de Spielberger State-Trait Anxiety Inventory, STAI-DY. Handleiding bij de Zelf-Beoordelings-Vragenlijst. Swets \& Zeitlinger B.V.

Vasey, M. W., \& Dadds, M. R. (2001). An introduction to the developmental psychopathology of anxiety. In M. W. Vasey \& M. R. Dadds (Eds.), The developmental psychopathology of anxiety (pp. 3-26). Oxford: Oxford University Press.

Warren, S. L., Huston, L., Egeland, B., \& Sroufe, L. A. (1997). Child and adolescent anxiety disorders and early attachment. Journal of the American Academy of Child and Adolescent Psychiatry, 36, 637-644.

Whaley, S. E., Pinto, A., \& Sigman, M. (1999). Characterizing interactions between anxious mothers and their children. Journal of Consulting and Clinical Psychology, 67, 826-836.

Wood, J. J., McLeod, B. D., Sigman, M., Hwang, W. C., \& Chu, B. C. (2003). Parenting and childhood anxiety: theory, empirical findings, and future directions. Journal of Child Psychology and Psychiatry, 44, 134-151. 